\title{
Cutaneous Manifestation of Systemic Lupus Erythematosus [SLE], Correlation with Specific Organ Involvement, Specific Auto Antibodies and Disease Activity and Outcome
}

\section{Fathia Ehmouda zaid ${ }^{1 *}$ and Naziha Abudsalam ${ }^{2}$}

${ }^{1}$ Department of Rheumatology, Benghazi University, Libya

${ }^{2}$ Department of Medicine, Benghazi University, Libya

\begin{abstract}
Background: Cutaneous lesions are important as a diagnostic aid as these account for 4 out of 11 revised American Rheumatism Association criteria for disease classification Cutaneous manifestation of systemic lupus erythematosus $(74.4 \%)$ and most patients had Butterfly rash $(48.8 \%)$, Photosensitivity $(41.9 \%)$, acute cutaneous lupus erythematosus (SCLE) $(32.6 \%)$, Discoid lupus $(20.9 \%)$, Nail lesions (16.3\%), Alopecia $(23.3 \%)$, oral nasal ulcer $(37.2 \%)$, purpuric rash (23.3\%), Raynaud phenomenon (16.3\%), Livedo reticularis (9.3\%), Telangiectasia's $(4.6 \%)$, and Urticarial lesion $(2.3 \%)$. Lupus profundus $(2.3 \%)$, Cutaneous manifestation of systemic lupus erythematosus are association with disease activity (97.7\%), Cutaneous manifestation of systemic lupus erythematosus are association with musculoskeletal (MSK) $(62.8 \%)$, Renal disease (27.9\%), Hematologic disease (23.3\%), Serositis $(9.3 \%)$, Neurologic disease (14\%), and cardiac disease $(9.3 \%)$,
\end{abstract}

Results: Cutaneous manifestation of systemic lupus erythematosus are association with positive ANA (90.3\%) and negative ANA (9.3\%), positive ds DNA (74.4\%), positive Anti-Ro (69.8\%), positive Anti-La (9.3\%), positive Anti-SM $(48.8 \%)$,and positive Anti-RNP (39.5\%\%). outcome of cutaneous manifestation of systemic lupus are skin atrophy and scarring $(27.9 \%)$. pigmentation $(25.6 \%)$ and alopecia $(23.3 \%)$.

Conclusion: The cutaneous lesions can provide valuable diagnosis of systemic lupus erythematosus. The most cutaneous manifestations are epidermal lesion then mucous-cutaneous lesion then vascular lesion, are associated with disease activity, and associated with high titer auto antibodies.

Keywords: Cutaneous manifestations; Systemic lupus erythematosus; Disease activity

\section{Introduction}

Cutaneous lesions are important as a diagnostic aid as these account for 4 out of 11 revised American Rheumatism Association criteria for disease classification [1,2] The diagnosis of the cutaneous manifestations of systemic lupus erythematosus( SLE) is based on clinical, histopathology, and immunohistology, in addition, serum autoantibodies are considered immunologic markers for distinct clinical types of the illness. The cutaneous lupus erythematosus disease area and severity index (CLASI) is used as a clinical tool that standardizes the way disease activity is described and provides guidelines for identifying a clinical change; this clinical tool quantifies disease activity and damage in cutaneous lupus erythematosus [3]. The activity score is based on the erythema, scale, mucous membrane lesions, and non- scarring Alopecia.

\section{Cutaneous manifestations of Systemic Lupus Erythematosus (SLE)}

\section{Epidermal lesion:}

1-Butter fly rash

2-Discoid Lupus Erythematosus (DLE)

3-Photosensitivity

4-Sub acute Cutaneous Lupus Erythematosus

5-Alopecia

6-Lupus panniculitis/Lupus profundus

7-Bullous lesion

8-Nail lesion

9-Lichenoid DLE (LE/lichen planus overlap)
10-Neonatal lupus

Mucous membrane:

1-Gingivitis

2-Oral ulcers

3-Nasal ulcer

Vascular lesion:

1-Raynaud's phenomenon

2-Periungual telangiectasias

3-Livedo reticularis

4-Urticarial vasculitis

5-Purpura vasculitis

6-Telangiectasia, Jane way lesions, Osler's nodes, Chilblain lupus

7-Atrophie Blanche lesions

*Corresponding author: Fathia Ehmouda Zaid, Assistant Professor, Faculty of Medicine, Benghazi University, Libya, Tel: 0193424950; E-mail: fatehmoda@yahoo.com

Received: December 03, 2015; Accepted: May 13, 2016; Published: May 17, 2016

Citation: Zaid FE, Abudsalam N (2016) Cutaneous Manifestation of Systemic Lupus Erythematosus [SLE], Correlation with Specific Organ Involvement, Specific Auto Antibodies and Disease Activity and Outcome. Dermatol Case Rep 1: 108. doi:10.4172/dmcr.1000108

Copyright: ( 2016 zaid FE, et al. This is an open-access article distributed under the terms of the Creative Commons Attribution License, which permits unrestricted use, distribution, and reproduction in any medium, provided the original author and source are credited. 
Citation: Zaid FE, Abudsalam N (2016) Cutaneous Manifestation of Systemic Lupus Erythematosus [SLE], Correlation with Specific Organ Involvement, Specific Auto Antibodies and Disease Activity and Outcome. Dermatol Case Rep 1: 108. doi:10.4172/dmcr.1000108

Page 2 of 3

The main purpose of this study is estimation cutaneous manifestation of systemic lupus erythematosus, correlation with disease activity, immunology test, specific organ involvement and outcome in Libyan patients.

\section{Patient and Methods}

This study was carried out at the Rheumatology department, Benghazi University, $7^{\text {th }}$ October -hospital, Libya, Follow up study (43) patients diagnosed as systemic lupus erythematosus (SLE) according to the American College of Rheumatology (ACR), in between January 2010 and December 2012, these patients were studied clinically for the presence of cutaneous manifestation by use The Cutaneous Lupus Erythematosus Disease Area and Severity Index (CLASI) is clinical tool that standardizes the way disease activity is described and provides guidelines for identifying a clinical change, this clinical tool quantifies disease activity and damage in cutaneous lupus erythematosus. The activity score is based on the erythema, scale, mucous membrane lesions, and non-scarring alopecia [3], and use immunology test ANA positivity was more than 1:160, anti-DNA Serum compliment levels (C3, C4), anti-ENA, and use SLEDAI.

\section{Results}

Forty-three patients diagnosed with systemic lupus erythematosus were included in the study. Patients' clinical characteristics are shown below (Table 1). The age of the study patients ranged from (18-55 years), $\mathrm{M}=(17 \pm 35 \mathrm{Y}), 42(97.7 \%)$ were female, $39(90.7 \%)$ were white and 4 (9.3\%) were black. Prevalence of Cutaneous manifestation of systemic lupus erythematosus was $32(74.4 \%)$. The most common Cutaneous manifestations of systemic lupus erythematosus in the study were as follow Butterfly rash 21 (48.8\%), then Photosensitivity 18 (41.9\%), then Sub-acute cutaneous lupus erythematosus (SCLE) 14 (32.6\%), then Discoid lupus 9 (20.9\%) out of which preceding development of SLE $2(4.6 \%)$ and $7(16.3 \%)$ meet criteria for diagnoses of SLE, then nail lesions 7 (16.3\%), then involvement oral-nasal ulcer 16 (37.2\%), then purpuric rash10 (23.3\%), then Raynaud's phenomenon 7 (16.3\%) and Livedo reticularis 4 (9.3\%). Most Cutaneous manifestation of systemic lupus erythematosus in association with active disease 42 (97.7\%). Most Cutaneous manifestation of systemic lupus erythematosus are association with musculoskeletal (MSK) 27 (62.8\%), then Renal disease 12 (27.9\%), then Hematologic (14\%), then Serositis 4 (9.3\%), and cardiac disease 10 (23.3\%) then Neurologic disease 6 disease 4 (9.3\%). Laboratory findings are summarized in (Tables 2 and 3 ) Cutaneous manifestation of systemic

\begin{tabular}{|c|c|}
\hline Age & $\mathbf{1 8 - 5 5}$ years $\mathbf{M =}[\mathbf{1 7 \pm 3 5 Y}]$ \\
\hline Sex & female 42 [97.7\%] \\
\hline Racial & White $39[3.2 \%]$ \\
\hline & Black 4 [9.3\%] $]$ \\
\hline $\begin{array}{c}\text { Cutaneous Manifestation of } \\
\text { Systemic Lupus } \\
\text { Erythematosus }\end{array}$ & $32[74.4 \%]$ \\
\hline Disease Activity & $42[97.7 \%]$ \\
\hline Musculoskeletal & $27[62.8 \%]$ \\
\hline (MSK) & $12[27.9 \%]$ \\
\hline Renal Disease & $10[23.3 \%]$ \\
\hline Hematologic Disease & $4[9.3 \%]$ \\
\hline Serositis & $6[14 \%]$ \\
\hline Neurologic Disease & $4[9.3 \%]$ \\
\hline Cardiac Disease & \\
\hline
\end{tabular}

Table 1: Clinical characteristics of patients in Systemic Lupus Erythematosus [SLE].

\begin{tabular}{|l|c|c|}
\hline \multicolumn{1}{|c|}{ Epidermal lesion } & N & $\%$ \\
\hline Butter fly rash & 21 & $48.80 \%$ \\
\hline Discoid lupus & 9 & $20.9 \%$ \\
\hline Photosensitivity & 18 & $41.9 \%$ \\
\hline SCLE & 14 & $32.6 \%$ \\
\hline SCLE Sub-Acute Cutaneous Lupus Erythematosus & & \\
\hline Alopecia & 10 & $23.3 \%$ \\
\hline Lupus profundus & 1 & $2.3 \%$ \\
\hline Nail lesion & 7 & $16.3 \%$ \\
\hline Ц)Mucosal ulcer & 16 & $37.2 \%$ \\
\hline Щ)Vascular lesion & & \\
\hline Raynaud's phenomenon & 7 & $16.3 \%$ \\
\hline Livedo reticularis & 4 & $9.3 \%$ \\
\hline Telangiectasias & 2 & $4.6 \%$ \\
\hline purpuric rash & 10 & $23.3 \%$ \\
\hline Urticarial vasculitis & 1 & $2.3 \%$ \\
\hline
\end{tabular}

Table 2: Cutaneous manifestation of systemic lupus erythematosus.

\begin{tabular}{|c|c|c|c|}
\hline $\begin{array}{c}\text { Positive auto } \\
\text { antibodies }\end{array}$ & $\%$ & $\begin{array}{c}\text { Cutaneous } \\
\text { manifestation }\end{array}$ & $\begin{array}{c}\text { Non cutaneous } \\
\text { manifestation }\end{array}$ \\
\hline ANA & $\begin{array}{c}39 / 43 \\
(90.7 \%)\end{array}$ & $28 / 43(65.1 \%)$ & $11 / 43(25.6 \%)$ \\
\hline DSDNA & $\begin{array}{c}32 / 43 \\
(74.4 \%)\end{array}$ & $26 / 43) 60.4 \%)$ & $6 / 43(14 \%)$ \\
\hline RNP & $\begin{array}{c}17 / 43 \\
(39.5 \%)\end{array}$ & $13 / 43(30.2 \%)$ & $4 / 43(9.3 \%)$ \\
\hline Anti-SM & $\begin{array}{c}21 / 43 \\
(48.8 \%)\end{array}$ & $16 / 4(37.2 \%)$ & $5 / 43) 11.6 \%)$ \\
\hline Anti -RO & $\begin{array}{c}30 / 43 \\
(69.8 \%)\end{array}$ & $22 / 43(51.2 \%)$ & $8 / 43) 18.6 \%)$ \\
\hline Anti- LA & $4 / 43(9.3 \%)$ & $3 / 43(6.9 \%)$ & $1 / 43(2.3 \%)$ \\
\hline
\end{tabular}

Table 3: Correlation between auto antibodies and cutaneous manifestation of SLE.

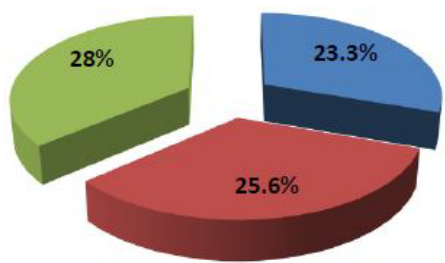

- alopecia

pigmentation

a skin atrophy and scarring

Figure 1: Outcome of cutaneous manifestation of systemic lupus erythematosus

lupus erythematosus are association with positive ANA (90.3\%) and negative ANA (9.3\%), positive ds DNA (74.4\%), positive Anti-Ro (69.8\%), positive Anti-La (9.3\%), positive Anti-SM (48.8\%), and positive AntiRNP (39.5\%\%). We demonstrated (Figure 1) Clinical course of cutaneous manifestations are progression into skin atrophy and scarring $12(27.9 \%)$ then pigmentation $11(25.6 \%)$ and alopecia $10(23.3 \%)$.

\section{Discussion}

The skin and mucous membranes are involved at some point in over $80 \%$ of patients with systemic lupus erythematosus (SLE) [4] Cutaneous manifestation of systemic lupus erythematosus is characterized by an epidermal lesion. Vascular lesion and Mucous membrane lesion, [5] Cutaneous illness often precedes the systemic involvement, giving the opportunity to the dermatologist to recognize the disease process much before the systemic complaints are expressed. This will allow the institution of appropriate management prevent the subsequent morbidity and mortality [6]. Skin lesions in patients with SLE are important disease manifestations which can Diagnostic aid as well as prognostic information, in the present study prevalence of 
Citation: Zaid FE, Abudsalam N (2016) Cutaneous Manifestation of Systemic Lupus Erythematosus [SLE], Correlation with Specific Organ Involvement, Specific Auto Antibodies and Disease Activity and Outcome. Dermatol Case Rep 1: 108. doi:10.4172/dmcr.1000108

cutaneous involvement was (74.4\%), majority initial presentation and (4.6\%) preceding development of SLE, Similarly in neuromas studies [7-9]. Butterfly rash and Photosensitivity were most common lesion similarly in Arabian studies [10-12] than European studies [13-15] this variation may be attributable to different climatic conditions. Nail lesions, included onycholysis pitting nail, dystrophic nail are common seen in our study, which contributed to chronicity of disease, other lesion like splinter hemorrhages and peri ungual erythema was not seen in our study. The oral and nasal ulcers of systemic lupus Different figures of the incidence Seen by conducted studies [16,17]. Raynaud's phenomenon and purpuric rash were common cutaneous vasculitis which was much less than from European studies due to different climate condition. Most Cutaneous manifestation of systemic lupus erythematosus is association with Musculoskeletal (MSK). Most Cutaneous manifestation of systemic lupus erythematosus are association with positive ANA and Anti-ds DNA antibodies which are specific for the diagnosis [18] and association with high titer auto antibodies and positive anti-Ro, anti-La, and anti-RNP antibodies more likely to have cutaneous involvement. Skin lesions in these patients produce considerable morbidity by producing alopecia, scarring lesions, disfigurement, hyper pigmentation, etc. [19]. Hyper pigmentation was noted $25.6 \% \%$ of our study which higher than reported in other European studies. This difference could be due to excessive exposure to sunlight in our country.

\section{Conclusion}

The cutaneous lesions can provide valuable diagnosis of systemic lupus erythematosus the most cutaneous manifestations are epidermal lesion include butterfly rash, photosensitivity, and then mucous-cutaneous lesion then vascular lesion, the most cutaneous manifestations are associated with disease activity, and associated with high titer auto antibodies. Clinical course of cutaneous manifestations are variable from mild skin lesion in to sever skin lesion with dermal damage like hyper pigmentation, skin atrophy scarring and alopecia.

\section{References}

1. Walling $H$, Sontheimer $D$ (2009) Cutaneous lupus erythematosus: issues in diagnosis and treatment. Am J Clin Dermatol 10: 365-381.
2. Tan E, Cohen S, Fries F (1982) The 1982 revised criteria for classification of SLE. Arthritis Rheum 25:1271-1277.

3. Klein R, Moghadam K, LoMonico J (2011) Development of the CLASI as a too to measure disease severity and responsiveness to therapy in cutaneous lupus erythematosus. Archives of Dermatology 147: 203-208.

4. Patel P, Werth V (2002) Cutaneous lupus erythematosus: a review. Dermato Clin 20: 373

5. Francès C, Barete S, Ayoub N, Piette J (2003) Classification of dermatologic manifestations in lupus erythematosus. Ann Med Interne 154: 33-44.

6. Beutner E, Blaszczyk M, Jablonska S, Chorzelski P, White D, et al. (1993) Preliminary, dermatologic first step criteria for lupus erythematosus and second step criteria for systemic lupus erythematosus. Int J Dermatol. 32: 645-651.

7. Font J, Bosch X, Ingelmo M, Herrero C, Bielsa I, et al. (1990) Acquired icthyosis in a patient with SLE. Arch Dermatol 126: 829.

8. Akhter J, Khan M (1992) SLE in Pakistan. Specialist 9: 25-27.

9. Kole A, Ghosh A (2009) Cutaneous manifestations of systemic lupus erythematosus in a tertiary referral center .Indian J Dermatol 54: 132-136.

10. Hanan F (2010) Cutaneous manifestations of systemic lupus erythematosus A retrospective study from Egypt in Gulf. Journal of Dermatology and Venereology 17

11. Uthman I, Nasr F, Kassak K, Masri F (1999) Systemic lupus erythematosus in Lebanon. Lupus 8:713-715.

12. Al-Jarallah K, Al-Awadi A, Siddiqui H (1998) Systemic lupus erythematosus in Kuwait- hospital based study. Lupus 7:434-438.

13. Yell J, Mbuagbaw J, Burge M (1996) Cutaneous manifestations of systemic lupus erythematosus. Cutaneous manifestations of SLE. British J Dermatol 135: 355-362.

14. Cardinali C, Caproni M, Bernacchi E, Amato L, Fabbri P, et al. (2000) The spectrum of cutaneous manifestations in lupus erythematosus-the Italian experience Lupus 9:417-423.

15. Cervera R, Jimenez S, Font J, Ingelmo M (2003) The epidemiology of SLE: a review of the current data with special emphasis on the lessons from the 'Eurolupus Cohort'. J Rheumatol 6:150-157.

16. Saurit V, Campana R, Ruiz A, Ducasse C, Bertoli A, et al. (2003) Mucocutaneous lesions in patients with systemic lupus erythematosus. Medicina 63: 283-287.

17. Dubois $L$, Tuffanelli $L$ (1964) Clinical manifestation of SLE Computer analysis of 520 cases. J Am Med Assoc 190:104-111.

18. Carty G (1986) Autoantibodies and their relation to rheumatic disease Advances in rheumatology. Med Clin North Am 70:237-256.

19. Quinn E, Cole J, Many H (1972) Problems of disability in patients with chronic skin disease. Arch Dermatol 105:35-40. 